\title{
The relationship between science and religion
}

\author{
Lewis Wolpert * \\ Department of Cell and Development Biology, \\ University College, London, United Kingdom
}

There is no connection between science and religion. Science, unlike religion, is based on evidence; and, in contrast to the many religions, there is just one science. All science had its origin in Greek civilisation. There is no ethics in scientific theories or discoveries, but ethical issues can arise when science is applied to technology. Religion does raise ethical issues in relation to science, particularly in relation to human embryonic research. While religion makes no contribution to science, I wish to provide a scientific explanation for the origin of religious beliefs and mystical minds, based on the evolution of human causal beliefs

Science is quite different from religion, which is based on faith rather than on evidence or logic. Science is a different way of interpreting the world from religion in that it relies on reason applied to empirical observations instead of faith in external authorities and personal revelation. Science and religion are thus incompatible, despite claims to the contrary. Scientific beliefs are special, and different from any other kind of thinking, because scientific thinking is not programmed in our brains in the way that religious thinking is, as discussed below. Scientific thinking does not deny the possibility of the existence of God, but does claim that there is no good evidence to support such a belief. Moreover, beliefs in miracles and the paranormal conflict with some of the basic tenets of physics, chemistry and biology (Wolpert 2006).

Science is also special is in that it different from technology. The elephant is a good example of complex technology: as evolution used no science, just the best survivors were selected and some or these were elephants. Similarly, our ancestors

Guest Researcher, Research Institute for Theology and Religion, University of South Africa, Pretoria, South Africa. 
selected tools like rocks without any scientific thinking. Science only began to have an impact on technology in the late 18th century, and the industrial revolution was not dependent on science. The steam engine was built from practical knowledge, not science. The great buildings of the Renaissance were not built scientifically but relied purely on technology. The fiveminute theorem was used: if, when the supporting structures were removed, the building remained intact for five minutes, it could be assumed it would last for a long time. Today, however, science has enormous influence on technology, from aeroplanes to medicines, mobile phones and computers.

All scientific thinking originates from ancient Greek civilisation (Lloyd 1987). Thales of Miletus seems to have been one of the very first scientists. He tried to explain the world, not in terms of myths, but in naturalistic terms that could be subjected to verification by observation and experiment. What, he wondered, might the world be made of? His unexpected answer was: water. Other Greeks disagreed with him and so began the first scientific debate. But more important than his answer was his explicit attempt to find a fundamental unity in nature. His approach expressed the belief that, underlying all the varied forms and substances in the world, there are unifying principles and causes. The process of objective, critical thinking about nature had begun. Never before, as far as we know, had someone put forward non-mystical ideas about the nature of the world that might offer universal explanations. For the first time there was a conviction that the natural world was controlled by what might be called 'laws', that is, that nature behaves as if there are unvarying regularities. Before the ancient Greeks human curiosity had focused entirely on humankind's relation to nature rather than on nature itself. The Greeks were the first to believe that humans and nature are not inextricably linked, which was the start of distanced curiosity about the world itself.

Perhaps this change is a reflection of the nature of ancient Greek society, which had its own traditions in law and literature. Its citizens cared about evidence, particularly in relation to politics and the law. Since science had very few practical applications, it was the love of knowledge that drove the Greeks to philosophy, which in its turn led to science. And this, as Aristotle made clear, required leisure, in which respect slaves may have 
played a key role. Aristotle made a major contribution to logical analysis, but his science was always wrong. The two great Greek scientists were Euclid and Archimedes. Euclid's geometry and Archimedes's mechanics are still with us and had an enormous influence on the development of science. Unlike religion, science evolved and some ideas were shown to be wrong.

By contrast, the Chinese put the emphasis on dialectic rather than formal logic (Lloyd \& Sivin 2002). They did not engage in speculative reasoning for its own sake. The Chinese had wonderful technology, but no science, and their beliefs were quite mystical. There was nothing like the Greek discussion of causality.

Einstein made this quite clear in a letter:

The development of Western science has been based on two great achievements, the invention of the formal logical system (in Euclidean geometry) by the Greek philosophers, and the discovery of the possibility of finding out causal relationships by systematic experiments (at the Renaissance). In my opinion one need not be astonished that the Chinese did not take these steps. The astonishing thing is that these discoveries were made at all (Price 1961).

Science is the best way we have discovered of understanding how the world works, as is demonstrated by the dramatic change in the way we live and the lifestyles of the developed nations over the last 100 years due to scientific applications to technology. Science is a communal enterprise, in which many individuals contribute to a common body of agreed knowledge, in contrast with the wide range of different religious beliefs around the world. There is no one scientific method. The sole requirements are internal consistency and explanations that fit the real world, as determined by observation and experiment. In science there is only one correct causal explanation for any set of observations. 
Nevertheless there are many styles of doing science, from theory to experiment to careful observation. Does science provide beliefs that are fundamentally true? In general the answer is yes, but it is important to realise that new evidence can always subject scientific conclusions to change. This willingness to change ideas to accommodate new data is another distinction between science and religion. Unlike religion, contemporary science is almost entirely independent of the particular culture in which it is done - science is universal, and there is no such thing as Western or Eastern science. If the history of science were to be rerun, it would be different, but the conclusions would be the same. DNA would still be the genetic material and Newton's laws would be rediscovered. The individual scientist, unlike the artist, is ultimately irrelevant, and the scientific genius merely speeds up progress. With rare exceptions, science is independent of cultural beliefs.

I want to emphasise one common feature of science that I think helps to explain why non-scientists can have severe difficulty with scientific beliefs. That is the unnatural nature of science (Wolpert 1993). Science does involve a special way of thinking about the nature of the world. Instead of just looking at obvious relations of cause and effect, like the breaking of a stone being attributable to the force of a hammer, science tries to understand mechanisms at a deeper level. This continual search for more fundamental explanations leads to serious problems, for the way the world works does not fit in with our day-today expectations, our common sense. Almost without exception any common sense view of the world is scientifically false. Obvious examples are the movement of the sun with respect to the earth, and the fact that the impact of a force on a body does not cause movement, but acceleration. How natural is it to believe, rightly, that at a constant 600 kilometres per hour, there is no force acting on a plane moving it ahead? And how well does Darwin's theory of evolution by random variation and natural selection fit in with common sense? And when it comes to 
basic physics like quantum theory it really is very difficult to understand if you are not a physicist.

Science basically conflicts with religion, for there is no evidence of a scientific nature for the existence of any gods or their supposed powers and special forces. As David Hume said in $A n$ enquiry into human understanding (1748), "No miracle should be believed unless the evidence was such that it would be miraculous not to believe in it." Yet many scientists have been and are religious. Isaac Newton is an outstanding example of a great scientist who was also deeply religious. He maintained that we must believe there is one God or supreme monarch. While denying that Christ was consubstantial and co-eternal with the Father, Newton asserted that Christ deserved worship as the redeemer. There is evidence in his manuscripts that he grounded his law of the universality of gravitation on the omnipresence of the one God, whose free will determined 'the frame of the world'. For him, it seems, the very beauty of the solar system reflects the aesthetic sensibility of God the creator. The law of gravity did not have to be an inverse square law had God not wished it to be so. Yet even today there is a small number of distinguished scientists who are religious (Larson \& Witham 1999).

The idea that humans have evolved from very simple and primitive creatures through random changes and natural selection is intolerable to those who believe that humans - as described in, for example, the Bible - were created by God. Ideas based on the religious concept of intelligent design have no relation to science. There is no evidence of a designer and the idea is based on faith. Curiously, ardent creationists attack Darwinian evolution theory partly by way of so-called scientific arguments. This is not to say that all the scientific questions relating to evolution have been solved. On the contrary, the origin of life itself, the evolution of the first cell from which all living beings evolved, is not yet understood, though there are important theories. But the fact that we do not have the answers to some Darwinian problems is no reason to believe there was a creator. Creationism explains nothing

Science provides by far the most reliable method for determining whether one's beliefs are valid. It may be difficult to accept, as it will often contradict common sense, but its value is 
inestimable. Science is the most successful human intellectual endeavour in history

William James (1956) was unpersuaded that science can provide the answers to all the questions that we are capable of asking, and in one sense he is right. However much we understand, there will always be unanswered questions. For example, what existed before the Big Bang? The limitation here may be that our ability to understand the world at the level of the very small and the very large is constrained by the finite construction of our brains. We must have the intellectual courage to live with such unanswered questions, rather than invent answers that have no basis other than in mystical experience. Whatever explanations science can provide, there will always be the unanswered question. But as Einstein said, the astonishing thing about the universe is how much of it we can apparently understand.

It is important to realise that reliable scientific beliefs have no intrinsic ethical or moral content - they refer to how the world is (Wolpert 2007). There is no ethics in Newton's laws, nor in the genetic code, nor in the fact that genes can affect our mental health. Yet religion can interfere with science when it comes to so-called ethical issues concerning experiments on the early human embryo. St Augustine believed that the soul entered the embryo at around 40 days. This belief held good for hundreds of years, but was changed recently by the Catholic Church without any justification, so that the fertilised egg is now believed to be a human being. There is no evidence for this, and twins can develop from the same egg. It is much more reasonable to assume that the embryo is a human being when it can survive outside the womb with minimum technical support. The religious view that the embryo is already a human being results in attempts to block experiments on early human embryos, such as isolating embryonic stem cells which have great potential for regenerative medicine.

While there is no relationship between religion and science, science can provide an explanation for the origin of religious beliefs in terms of Darwinian evolutionary theory. This is a theory which I am proposing and it is based on the evolution of causal beliefs in relation to tool making 
Why do people have the beliefs that they have? As Bacon commented in the 16th century, "For what a man had rather be true he more readily believes." Causal beliefs can determine how we behave. Beliefs, as distinct from knowledge, always carry a degree of uncertainty. Beliefs can be very unreliable. For example, many people believe themselves to be above average in practically every quality, from intelligence to kindness; so unravelling the basis of their beliefs is a complex matter. It is a human characteristic that we cannot tolerate not knowing the causes of important events that affect our lives. If you go to a doctor, the one thing you cannot tolerate is for the doctor to say, "I don't know what is wrong with you." When you are told what is wrong with you, you will tell yourself a story to explain why you got that illness. Religious beliefs are special and contain a supernatural element, usually a god.

Humans have a basic need to construct beliefs that account for important events in their lives and religion provides some of the basic explanations. This cognitive imperative evolved because it was an evolutionary advantage for human survival to have causal beliefs that led to tool making. It was technology that drove human evolution. The word 'belief' is not easy to define (Wolpert 2006). A characteristic of belief, unlike common knowledge, is that it is always graded with respect to our confidence in it: it has a true and false value, how right or wrong it is. One can think of causal belief as an explanatory tool for understanding the physical world, and it is programmed into our brains (Leslie 1995).

Causal understanding in children is a developmental primitive (Schlottmann et al. 2002). From the age of three months infants can apparently reason about physical causality. They reason about these events according to three principles which may be genetically determined: moving objects maintain both connectedness and cohesion, they do not break up or fuse; they move continuously and do not disappear and appear again without other objects in the way; they move together or interact only if they touch. There are many experiments to support this - for example, infants clearly understand that for a moving block to make another one move, it must make contact with it. At an early age children know that a moving object - a ball - can make another move on impact. This primitive concept 
of mechanics may be the key causal belief, which originally evolved in early humans. At 18 months infants are effectively using objects as tools. Children ask many questions about causes.

Animals, by contrast, have very limited causal beliefs, though they can learn to carry out complex tasks. According to Michael Tomasello (1999) humans, but no other primates, understand the causal and intentional relations that exist among external entities. One may illustrate the differences between chimpanzee and human thinking with the claim that non-human primates, seeing the wind blow and shaking a branch till the fruit falls, would never believe, from this, that they could shake the branch to get the fruit.

One might have thought that Wolfgang Kohler's experiments with chimpanzees showed just the opposite. His chimpanzees, some eighty years ago, could sometimes, perhaps with some training, stack boxes on top of each other to get a banana nailed to the ceiling. But Kohler himself acknowledged that the chimpanzees had no knowledge of the forces involved. For example, they would try to place one box on another along its diagonal edge; and if stones were placed on the ground so that the box toppled over, they never removed the stones.

Chimpanzees and apes are thus at the edge of causal understanding as shown by their use of simple tools, such as using a stone to break nuts or trimming a grass reed to get ants. But in no instance of stone tool use is there evidence of modifying the structure of the stone to improve its function.

The studies of Daniel Povinelli (2000) have shown that apes, for example, cannot select an appropriate tool for a simple physical manipulation without training. Nevertheless tamarin monkeys are able to correctly choose the right simple tool to get food and Hauser (2000) found that tamarin monkeys choose to pull a scarf that has the reward attached to it rather than one just close to it. New Caledonian crows manufacture and use several types of tools for extractive foraging of invertebrates, including straight and hooked sticks, and complex stepped-cut flat tools made from leaves (Chappell \& Kacelnik 2002)). So while animals like crows and some primates have some understanding of tool use, they have a very limited capacity for refining and combining objects to make better tools. 
The evolutionary advantage of causal beliefs in humans relates to the making and use of tools, both simple and complex. One cannot make even a slightly complex tool without a concept of cause and effect. By complex I mean a tool that has a well characterised form for the use to which it will be put and, even more importantly, any tool made out of two pieces put together, like a spear with a stone head. It is only with the emergence of causal beliefs that technology became possible, and it was technology - the ability to physically interact with the environment - that made life easier. Just consider things as apparently as simple as a knife, a basket and the wheel.

Darwin was insistent on the continuity of mental skills as observed in chimpanzees, for example the use of sticks to get ants. But he was forced to concede the point to the duke of Argyll, who claimed that the fashioning of an implement for a special purpose is absolutely peculiar to humans. Kenneth Oakley (1949) made it clear that humans may be distinguished as tool-making primates. Only humans effectively cause one object to interact with another or the environment in a multitude of different ways and thus invented technology, which effectively drove human evolution.

There is even evidence that specific regions of the human brain are associated with tool use. A key component of this ability, it has been suggested, is a causal operator in the brain, which may involve connections between the left frontal lobe and left orientation area. There is evidence from brain imaging studies that distinct brain regions are related to knowledge about different classes of objects, such as people, plants and tools (Johnson-Frey 2004). Stroke patients who have damage to these areas have great difficulty with causal thinking, and often do not know why something happened

The first stone tools are essentially flaked and smashedup quartz pebbles and the first known stone tool industry consisted of simple stone flakes (Schick \& Toth 1993). Even a modern human requires several hours to master tool making. A carefully controlled, sharp glancing blow is needed to initiate a fracture in making the tool and that requires a concept of cause and effect. It took at least a million years to advance from stone axes to other, more complex tools. By some 300000 years ago tool-making skills had accelerated and by the Middle Stone Age 
there is clear evidence of hafted tools, that is composites with the components joined together (Ambrose 2001). This was a major advance, since one clearly cannot make such a tool, joining quite different pieces together, without having a very clear concept of cause and effect. About 20000 years ago bows and arrows made their appearance, together with needles and sewing. Moreover, some of the tools were no longer merely extensions of common bodily movements. A hammer is essentially a weighted fist, and using a saw involves recognising a quite new causal principle.

Contrary to the emphasis I and others have put on tool use as a key factor in human evolution, there is a quite widely held view that primate brain evolution has been driven princepally by the demands of the social world rather than the demands of interacting with the physical environment. Robin Dunbar (2004) claims that there is growing consensus that primate brain evolution has been driven principally by the demands of the social world, interactions with the environment and particularly with other members of the group. He argues that human brain growth, language and intelligent behaviour were evolutionary changes related to the increasing social complexity of hominid community life. For Dunbar the evolution of language is intimately linked to its ability to facilitate the bonding of larger groups and cooperation within them. But without causal thinking about the interactions of objects I find it hard to see how improved social understanding could have been a real advantage, or how it could have led to technology.

Religious beliefs are universal, complex and variable, and their origin, acquisition and modification present a difficult problem. My suggestion is that they all had their origin in the evolution of causal beliefs, which in turn had its origins in tool use. Given causal beliefs, it was natural for our ancestors to ask 'why' questions about life and death. One needs to consider the lifestyle of the earliest humans. They were hunter-gatherers, and group activity and tool use were very important. A key proposal I wish to put forward is that once causal belief evolved in relation to tools, and language evolved, it was inevitable that people would want to understand the causes of all the events that affected their lives from illness, through changes in climate, to death itself. Once there was a concept of cause and effect 
ignorance was no longer bliss, and this could have led to religious beliefs. People wanted to know what caused the important events in their lives, what would happen in the future, and what action they should take. Uncertainty about major issues that affected their lives was as intolerable then as it is now. Religion provided causal understanding. Humans were the most obvious causal agents. Religion also offered the possibility of asking for help by praying.

Foremost, our ancestors wanted to know the causes of 'evil' and incomprehensible events. The one causative agent that our ancestors were sure about was their own and other people's actions, particularly those learnt from tool making and altering the environment. They are the most clear-cut examples of causes and led to belief in human-like gods.

In many religions there is a belief in a God who is like a person without a normal body, free, eternal, all-knowing and capable of doing anything. There are very few societies without religious beliefs, which strongly supports the idea that it had an evolutionary advantage. Religious beliefs were adaptive for two main reasons: they provided explanations for important events and also offered prayer as a way of dealing with difficulties.

Since causal beliefs that promote survival are partly programmed by our genes, could that not also be true of some aspects of religious beliefs that promote survival, particularly those that relate to mystical forces and even, perhaps to the gods themselves? Religious beliefs provided gods or ancestors who could be prayed to, and who might help to solve problems. Those with such beliefs may have been better adapted for survival if they were less anxious and healthier.

What is the relationship between religion and health? If it is positive, then religion could be an adaptive factor in evolution. Although the studies conducted so far should be regarded as tentative, the evidence is that there is an inverse relationship between pain intensity and religious beliefs (Koenif et al. 2001). This is consistent with the findings that those within a religious community enjoy better mental health, possible due to social support. There is also evidence that religious activities reduce psychological stress and promote well-being and optimism, and so help to reduce the bodily effects of stress such as that on the heart. 
Thus those with such beliefs most likely did better, and so were selected. That means that religion may be deep-rooted in our biology. Has religious belief, then, a genetic component? The Minnesota twin study did find that there was a genetic influence on whether an individual developed religious beliefs heritability was around 50 percent, which implies a significant genetic component. Almost every culture has a belief in a spiritual world that contains a god who can be prayed to and is in control of powerful forces.

One model proposes that activation of the autonomic nervous system - the one which is not directly under our control and which controls, for example, our heart rate and blood flow acts on those regions of the brain responsible for mental experience, such as the temporal lobes. These lobes are thought to modulate feelings and emotions. Evidence for a role of the temporal lobes in religious experience comes from epilepsy originating in these lobes, and their association with sudden religious conversions. It is suggested that St Teresa's visions may have been associated with temporal lobe epilepsy.

It is thus of great interest that there is evidence that electromagnetic stimulation of the brains of subjects caused tiny seizures in the temporal lobes. Many subjects had supernatural spiritual experiences, even religious ones, which included the sense of something or someone else in the room, distortion of their bodies, and religious feelings.

Religion is concerned with the supernatural and thus involves forces and causes beyond our normal experience of nature. This is something we need to understand. Humans might seek rewards through the supernatural if they are not obtainable by other means. Pascal Boyer (2001) considered what makes religious beliefs seem so natural to many people. His answer rejects the view that it is just people's wish to deal with misfortune or understand the universe, though he recognises the importance of gods reacting to one's behaviour. For him there is no simple answer and it involves a variety of cognitive processes which are used to account for evil events. $\mathrm{He}$ argues that an important aspect of religious notions is that they are products of the supernatural imagination, which in turn involves counterintuitive notions. 
A large number of people hold paranormal beliefs that invoke forces and causes outside both ordinary experience and science; they offer believers new powers. It is also not unreasonable to think that some religious beliefs are paranormal - consider Christ's miracles, his rising from the dead, and the supposed efficacy of prayer. Paranormal beliefs may partly be the result of trying to explain events for which no simple explanation seems possible, together with a preference for invoking mystical causes and forces. Some 30 percent of Americans believe in ghosts, 70 percent in angels, and as many as one in ten claims to have seen, or had contact with, a ghost. These experiences include not just ghostly apparitions but unusual smells, and the strong sense of someone or something being present. In addition 25 percent claim to have had had a telepathic experience, and 11 percent to have seen a flying saucer. Around 50 percent of the population believe in extrasensory perception.

Our brains, I suggest, are programmed for such beliefs. This genetic contribution may have programmed our brains to have spiritual and paranormal experiences easily. When viewed in this way, hallucinations and delusions may reflect a basic program in the brain that, for a variety of reasons, can be activated at inappropriate times. Thus religious experiences may have become linked to paranormal beliefs, delusions and hallucinations. Consider this statement by Timothy Leary after taking LSD: "I discovered that beauty, revelation, sensuality, the cellular history of the past, God, the Devil - all lie inside my body, outside my mind." How could LSD, a rather simple molecule, induce such experiences if the brain circuits for having such experiences are not already there?

Michael Schumaker (1995) refers to the 'paranormal belief imperative'. He argues that we are pre-eminently auto-hypnotic creatures and suggests that human beings are "a believing phenomenon, who must believe in order to live at all". Levy Bruhl's statement (1940) is very important in this connection: "There is a mystical mentality more marked and more easily observable among primitive societies than our own, but present in every human mind. That is a sense of an invisible power and a reality other than our normal reality. It is something fundamental and indestructible in human nature." 
Further evidence for this comes from studies of groups given the active ingredient of magic mushrooms, psilocybin. This can cause mystical and religious experiences, which implies that such circuits are in our brains. There may thus be some genetic tendency to have mystical and religious beliefs (Griffiths et al. 2006).

A rather different approach to the evolution of religious beliefs from that considered so far emphasises the social aspects of belonging to a religious community, and the extent to which this has advantages for the members. Wilson (2002) looks at human society as an organism in its own right, and thus at the evolution of society in Darwinian terms. This approach is somewhat flawed, since there is no way in which a society, religious or otherwise, conforms to the evolution of organisms, as there is nothing equivalent to replication of genes or their programming of organismic behaviour in a society.

Sloan Wilson (2002), attempts to understand a religious community in relation to its environment from an evolutionary perspective, focusing on John Calvin's views of Christianity in Geneva in the 16th century. How adaptive, he asks, was Calvinism for the inhabitants of Geneva? Calvin placed equal emphasis on people's relationship with God and their relations with other people such as duties of charity owed to one's neighbours. Calvinism included, of course, the Ten Commandments, which may help societies to have adaptive belief systems that lead to behaviour similar to cooperation with one's neighbours. At the same time the system must cope with the problem of some individuals exploiting others' good behaviour.

But it remains far from clear in what evolutionary sense Calvin's society was adaptive in the evolutionary sense of ensuring reproduction and survival of its citizens. Its administration may have been very fair, and individuals may have liked many aspects of it, but from an evolutionary viewpoint this is irrelevant, since only reproductive advantage matters. The Balinese goddess who helps with irrigation of the rice fields and ensures cooperation in the distribution of the water offers a better example. This belief coordinates the activities of thousands of farmers for their mutual benefit. In light of this thinking Wilson suggests it is plausible to argue that we are 
genetically programmed to have a psychology sympathetic to the adaptive rules of religion.

\section{Bibliography}

Alper, M 2000. The 'God' part of the brain. New York: Rogue Press.

Ambrose, S H 2001. Paleolithic technology and human evolution. Science 291, 1748-1752.

Boyer, P 2001 Religion explained: the evolutionary origins of religious thought. New York: Basic Books.

Chappell, J \& Kacelnik, A 2002. Tool selectivity in a nonprimate, the New Caledonian crow (Corvus moneduloides). Animal Cognition 5, 71-78.

Dunbar, R 2004. The human story. London: Faber.

Griffiths, R R, Richards, W A, McCann, U \& Jesse, R 2006. Psilocybin can occasion mystical-type experiences having substantial and sustained personal meaning and spiritual significance. Psychopharmacology 187, 268-83.

Hauser, M 2000. Wild minds. London: Lane.

Kendler, K S, Liu, X Q, Wang, A X, Wang, D W \& Wang, J N 2003. Dimensions of religiosity and their relationship to lifetime psychiatric and substance abuse disorders. American Journal of Psychiatry 160, 496-502.

Koenig, H G, McCullough, M E \& Larson D B 2001. Handbook of religion and health. Oxford: Oxford University Press.

James, W 1897, 1956. The will to believe. New York: Dover.

James, W 1902, 1982. The varieties of religious experience. London: Penguin.

Johnson-Frey, S H 2001. The neural basis of complex tool use in humans. Trends in Cognitive Science, 71-78.

Larson, E J \& Witham, L 1999. Scientists and religion in America. Scientific American, September, 72-82.

Leslie, A M 1995. A theory of agency, in Sperber, D., Premak, D. \& Premak, A. J. (eds), Causal cognition. Oxford: Clarendon Press, 121-142.

Levy-Bruhl, L 1940 Notebooks on primitive mentality. Oxford: Blackwell. 
Lloyd, G E R 1987. The revolution of wisdom: studies in the claims and practice of ancient Greek science. Berkeley, Cal.: University of California Press.

Lloyd, G \& Sivin, N 2002. The way of the word: science and medicine in early China and Greece. New Haven: Yale University Press.

Oakley, K 1949. Man the tool-maker. London: British Museum Press.

Povinelli, D J 2000. Folk physics for apes. Oxford: Oxford University Press.

Price, D S 1961. Science since Babylon. New Haven: Yale University Press.

Schick, K D \& Toth, N 1993. Making silent stones speak. London: Weidenfeld \& Nicolson.

Schlottmann, A, Allen, D, Linderoth, C \& Hesketh, S 2002. Children's intuitions of perceptual causality. Child Development, 73,1656-1677.

Schumaker, J F 1995. The corruption of reality. New York: Prometheus.

Sperber, D, Premak, D \& Premak, A J (eds) 1995. Causal cognition: a multidisciplinary debate. Oxford: Clarendon Press.

Tomasello, M 1999. The cultural origins of human cognition. Cambridge: Harvard University Press.

Wilson, D S 2002. Darwin's cathedral. Chicago: University of Chicago Press.

Wolpert, L 1993. The unnatural nature of science. London: Faber.

Wolpert, L 2003. Causal belief and the origin of technology. Philosophical Transactions Royal Society, London. A. 361, 1709-1719.

Wolpert, L 2006. Six impossible things before breakfast. London: Faber.

Wolpert, L 2007. Is cell science dangerous? Journal of Medical Ethics 33, 345-348. 
